Retraction

\title{
Retracted: Photovoltaic Performance of ZnO Nanosheets Solar Cell Sensitized with Beta-Substituted Porphyrin
}

\section{Journal of Nanomaterials}

Received 21 August 2020; Accepted 21 August 2020; Published 11 December 2020

Copyright (c) 2020 Journal of Nanomaterials. This is an open access article distributed under the Creative Commons Attribution License, which permits unrestricted use, distribution, and reproduction in any medium, provided the original work is properly cited.

Journal of Nanomaterials has retracted the article titled "Photovoltaic Performance of $\mathrm{ZnO}$ Nanosheets Solar Cell Sensitized with Beta-Substituted Porphyrin" [1], at the request of the author as it is identical in the title and the technical content with another article [2] submitted to Solar Energy with the following information.

\section{References}

[1] A. Mahesh, "Photovoltaic Performance of $\mathrm{ZnO}$ Nanosheets Solar Cell Sensitized with Beta-Substituted Porphyrin," Journal of Nanomaterials, vol. 2011, Article ID 301873, 9 pages, 2011.

[2] S. Suresh, A. Pandikumar, S. Murugesan, R. Ramaraj, and S. P. Raj, "Photovoltaic performance of solid-state solar cells based on $\mathrm{ZnO}$ nanosheets sensitized with low-cost metal-free organic dye," Solar Energy, vol. 85, no. 9, pp. 1787-1793, 2011. 


\title{
Photovoltaic Performance of ZnO Nanosheets Solar Cell
} Sensitized with Beta-Substituted Porphyrin

\author{
Arumugam Mahesh
}

Saveetha School of Engineering, Saveetha University, Chennai 602105, India

Correspondence should be addressed to Arumugam Mahesh, maheshbubathi15@yahoo.co.in

Received 2 August 2010; Revised 20 January 2011; Accepted 9 February 2011

Academic Editor: Christian Brosseau

Copyright () 2011 Arumugam Mahesh. This is an open access article distributed under the Creative Commons Attribution License, which permits unrestricted use, distribution, and reproduction in any medium, provided the original work is properly cited.

The photoanode of dye-sensitized solar cell (DSSC) was fabricated using two-dimensional ZnO nanosheets (2D ZnO NSs) sensitized with beta-substituted porphyrins photosensitizer, and its photovoltaic performance in solid-state $\mathrm{DSSC}_{\text {with }} \mathrm{TiO}_{2}$ nanotubes $\left(\mathrm{TiO}_{2} \mathrm{TNs}\right)$ modified poly (ethylene oxide) (PEO) polymer electrolyte was studied. The ZnO NSs were synthesized through hydrothermal method and were characterized through high-resolution scanning electron microscopy (HRSEM), diffused reflectance spectra (DRS), photoluminescence spectra (PL), and X-ray diffraction (XRD) analysis. The crystallinity of the polymer electrolytes was investigated using X-ray diffraction analysis. The photovoltaic performance of the beta-substituted porphyrins sensitized solar cells was evaluated under standard AM1.5G simulated illumination $\left(100 \mathrm{~mW} \mathrm{~cm}^{-2}\right)$. The efficiency of energy conversion from solar to electrical due to $2 \mathrm{D} \mathrm{ZnO}$ NSs based DSSCs is $0.13 \%$, which is about 1.6 times higher than that of the control DSSC using $\mathrm{ZnO}$ nanoparticles $\left(\mathrm{ZnO}\right.$ NPs) as photoanode $(0.08 \%)$, when $\mathrm{TiO}_{2}$ NTs fillers modified PEO electrolyte was incorporated in the DSSCs. The current-voltage $(I-V)$ and photocurrent-time $(I-T)$ curves proved stable with effective collection of electrons, when the $2 \mathrm{D} \mathrm{ZnO}$ nanostructured photoanode was introduced in the solid-state DSSC.

\section{Introduction}

Dye-sensitized solar cells (DSSCs) represent a key class of cell architecture that has emerged as a promising candidate for the development of next-generation solar cells. It possesses advantage of low cost and ease of fabrication compared to the traditional silicon solar cells. In fact, DSSCs with a power conversion efficiency of over 10\% have been achieved using a photoanode of $\mathrm{TiO}_{2}$ nanocrystalline films sensitized by ruthenium-based dyes [1-3], with suitable engineering and optimization of the nanostructure for its optical, electrical, and morphological properties together with light-harvesting characteristics, and so forth. These cells were shown to deliver relatively high power $[4,5]$.

$\mathrm{ZnO}$ is a wide band gap $(3.37 \mathrm{eV})$ semiconductor which is much used in short wavelength optoelectronic applications, has also been used as photoanode materials in DSSCs due to its high charge carrier (electron) mobility, transparent to visible light, and can be made highly conductive by doping and more flexibility in synthesis and also due to its advantageous morphology in comparison with $\mathrm{TiO}_{2}[6]$.
The nanoporous dye-sensitized $\mathrm{ZnO}$ films have shown that ultrafast electron injection takes place from the dye into the conduction band of $\mathrm{ZnO}$ particles [7, 8]. The photoanode fabricated from semiconductor materials need to provide, in addition to a wide band gap and high charge carrier mobility, high surface area for efficient dye sensitization and light harvesting, which can only be achieved by a nanostructured electrode. $\mathrm{ZnO}$ is a versatile functional material having a diverse group of growth morphologies, such as nanocombs, nanorings, nanohelixes, nanosprings, nanobelts, nanowires and nanocages. Besides the conventional one-dimensional (1D) nanorods, nanowires and nanotubes, a diversity of 2D nanomaterials of $\mathrm{ZnO}$ such as nanodisks, nanosheets, nanoplates and nanofilms have emerged recently $[9,10]$. Therefore, $\mathrm{ZnO}$ seems to be a promising material for solar cell and has the advantage of easy synthesis of controlled nanostructures over other metal oxides [11]. $\mathrm{ZnO}$ arrays of 1D nanostructures, such as nanowires and nanotubes, have been widely utilized to significantly enhance the electron transport velocity within the photoanode. This enhancement is achieved by providing a direct conduction pathway for the 
rapid collection of photogenerated electrons, which reduce the number of interparticle hops. But insufficient internal surface area of these 1D nanostructure arrays limits the power conversion efficiency at a relatively low level owing to deficient dye loading and light harvesting [12-14]. 2D $\mathrm{ZnO}$ nanostructures have also been studied for DSSCs applications on account of the fact that they also have a large specific surface area. $2 \mathrm{D}$ nanosheets can be regarded as a new class of nanostructured materials due to their high anisotropy and nanometer-scale thickness, possessing interesting properties [15-17]. DSSCs constructed using nanosheets films of upright-standing $\mathrm{ZnO}$ exhibit a very high conversion efficiency of $3.9 \%$ [18].

Dye-sensitized solar cells usually have an electrolyte (redox system) to regenerate the dye by electron donation to its ground state after excitation. The composition of a stable and efficient electrolyte also remains as one of the key challenges for practical applications. The problem is closely related to the solvent evaporation and leakage of the electrolyte, which directly affect the stability and long-term operation of the cell. In this regard, efforts have been made to replace the liquid electrolyte with materials such as molten salts, inorganic p-type semiconductors, ionic conducting polymers, and organic hole transport materials $[19,20]$. Polymers are also being used as the structure-directing agent to control the nucleation, growth, and alignment of crystals [21]. Beta-substituted porphyrins are considered in this paper as a sensitizer since they are cheaper than the commonly used ruthenium bipyridyl complexes. The structure of beta-substituted porphyrins is given in Figure 1. The photophysical study revealed that these nanorings exhibit weakly coupled chromophores and longer fluorescent lifetimes, which is an apparent advantage in the process of efficient excited energy transfer.

In this study, the photoanode of the DSSCs was fabricated shown in Figure 2, using $2 \mathrm{D} \mathrm{ZnO}$ NS sensitized with betasubstituted porphyrins dye, and its ability to convert solar energy to electrical energy in solid-state DSSCs was studied with $\mathrm{TiO}_{2}$ NTs modified PEO solid-state polymer electrolytes. Since low-dimensional $\mathrm{ZnO}$ nanostructures have exclusive and favorable properties they are considered more suitable for applications in solar energy conversion assemblies.

\section{Experimental Details}

2.1. Chemical Reagents. Chemical reagents such as zinc acetate, zinc nitrate hexahydrate, sodium hydroxide and oxalic acid, $\mathrm{TiO}_{2}$ were purchased from Merck. Poly (ethylene oxide) was purchased from Aldrich. Beta substituted porphyrins was received from Alfa aesar, and all the rest of the chemicals used in this work were of analytical grade.

2.2. Preparation of $\mathrm{ZnO}$ Nanostructures. The $\mathrm{ZnO}$ nanoparticles were prepared by the following procedure. Typically, $0.1 \mathrm{M}$ zinc acetate was mixed with $0.1 \mathrm{M}$ aqueous solution of oxalic acid, and allowed to stir for about $12 \mathrm{~h}$. The white precipitates obtained thus, were filtered and washed with acetone and distilled water to remove impurities and dried in a vacuum oven at $120^{\circ} \mathrm{C}$ for $6 \mathrm{~h}$ in order to remove water molecules. The $\mathrm{ZnO}$ nanoparticles were then calcinated over a temperature of $400-450^{\circ} \mathrm{C}$ in a muffle furnace in order to remove $\mathrm{CO}$ and $\mathrm{CO}_{2}$ from the compound. The $\mathrm{ZnO}$ NSs were prepared by the following procedure. Briefly, $3 \mathrm{~g}$ of $\mathrm{Zn}\left(\mathrm{NO}_{3}\right)_{2} \cdot 6 \mathrm{H}_{2} \mathrm{O}$ and $1.6 \mathrm{~g}$ of $\mathrm{NaOH}$ were dissolved separately in $80 \mathrm{~mL}$ of double distilled water. The zinc nitrate solution was added dropwise into the $\mathrm{NaOH}$ solution to form white slurry. The white slurry formed thus was kept at $80^{\circ} \mathrm{C}$ on a hotplate for $6 \mathrm{~h}$ without stirring. The resultant white precipitate was isolated through centrifugation at $5000 \mathrm{rpm}$ and repeatedly washed with double distilled water and ethanol several times. Finally the precipitate was vacuum dried at $60^{\circ} \mathrm{C}$ for $12 \mathrm{~h}$ and the resultant powder was used for further studies.

2.3. Preparation of $\mathrm{TiO}_{2}$ Nanotubes Modified PEO Polymer Electrolyte. The $\mathrm{TiO}_{2}$ NTs were prepared based on a hydrothermal method as described in the literature [22]. Briefly, $1 \mathrm{~g}$ of $\mathrm{TiO}_{2}$ nanopowder (P25, Degussa) was mixed with $42.5 \mathrm{~mL}$ of an aqueous solution of $10 \mathrm{M} \mathrm{NaOH}$. The resultant dispersion was heated for $72 \mathrm{~h}$ at $150^{\circ} \mathrm{C}$ in a Teflon lined autoclave. After cooling to room temperature, the $\mathrm{TiO}_{2}$ NTs were separated by filtration and washed with deionized double distilled water. Subsequently, the $\mathrm{TiO}_{2} \mathrm{NTs}$ were immersed in $0.1 \mathrm{M} \mathrm{HCl}$ solution for $3 \mathrm{~h}$, followed by washing with deionized double distilled water several times until the $\mathrm{pH}$ of the solution reached neutral value. After drying at $80^{\circ} \mathrm{C}$ in an oven, pure TNTs were obtained. The $\mathrm{TiO}_{2}$ NTs modified PEO polymer electrolyte was prepared according to the reported procedure with slight modification [23]. The prepared $\mathrm{TiO}_{2}$ NTs $(0.0383 \mathrm{~g})$ were dispersed in $50 \mathrm{~mL}$ of acetonitrile containing $\mathrm{I}^{-} / \mathrm{I}_{3}{ }^{-}$redox couple $(0.1 \mathrm{~g}$ $\mathrm{KI}$ and $0.019 \mathrm{~g} \mathrm{I}_{2}$ ). Then, $0.264 \mathrm{~g}$ of PEO (MW 1,000,000) was slowly introduced into the above mixture at constant stirring, and the stirring continued further for $24 \mathrm{~h}$ at ambient temperature. Finally, the electrolyte was placed in the vacuum oven to evaporate the solvent until giving a viscous paste.

2.4. Characterization Studies. Diffused reflectance spectra of $\mathrm{ZnO}$ NPs and ZnO NSs were obtained using an Agilent 8453 diode array UV-Vis spectrophotometer fitted with Labsphere diffused reflectance spectra accessory. X-ray diffraction (XRD) pattern of the samples was recorded on a Bruker AXS D8 Advance X-ray diffractometer with $\mathrm{CuK} \alpha$ radiation $(\lambda$ $=1.5404 \AA)$. High-resolution scanning electron microscopic (HRSEM) images were obtained using FEI Quanta FEG200 High-resolution scanning electron microscope. Oriel class-A solar simulator (M-91195A, Newport) employing ozone-free $450 \mathrm{~W}$ xenon lamp was used as a light source. A computercontrolled Autolab PGSTAT302N electrochemical workstation was employed for current-voltage measurements.

2.5. Fabrication and Evaluation of DSSC Performance. The prepared $\mathrm{ZnO}$ NSs $(2 \mathrm{~g})$ were ground in a porcelain mortar with $0.7 \mathrm{~mL}$ of double distilled water containing $67 \mu \mathrm{L}$ of acetylacetone (in order to prevent reaggregation of 


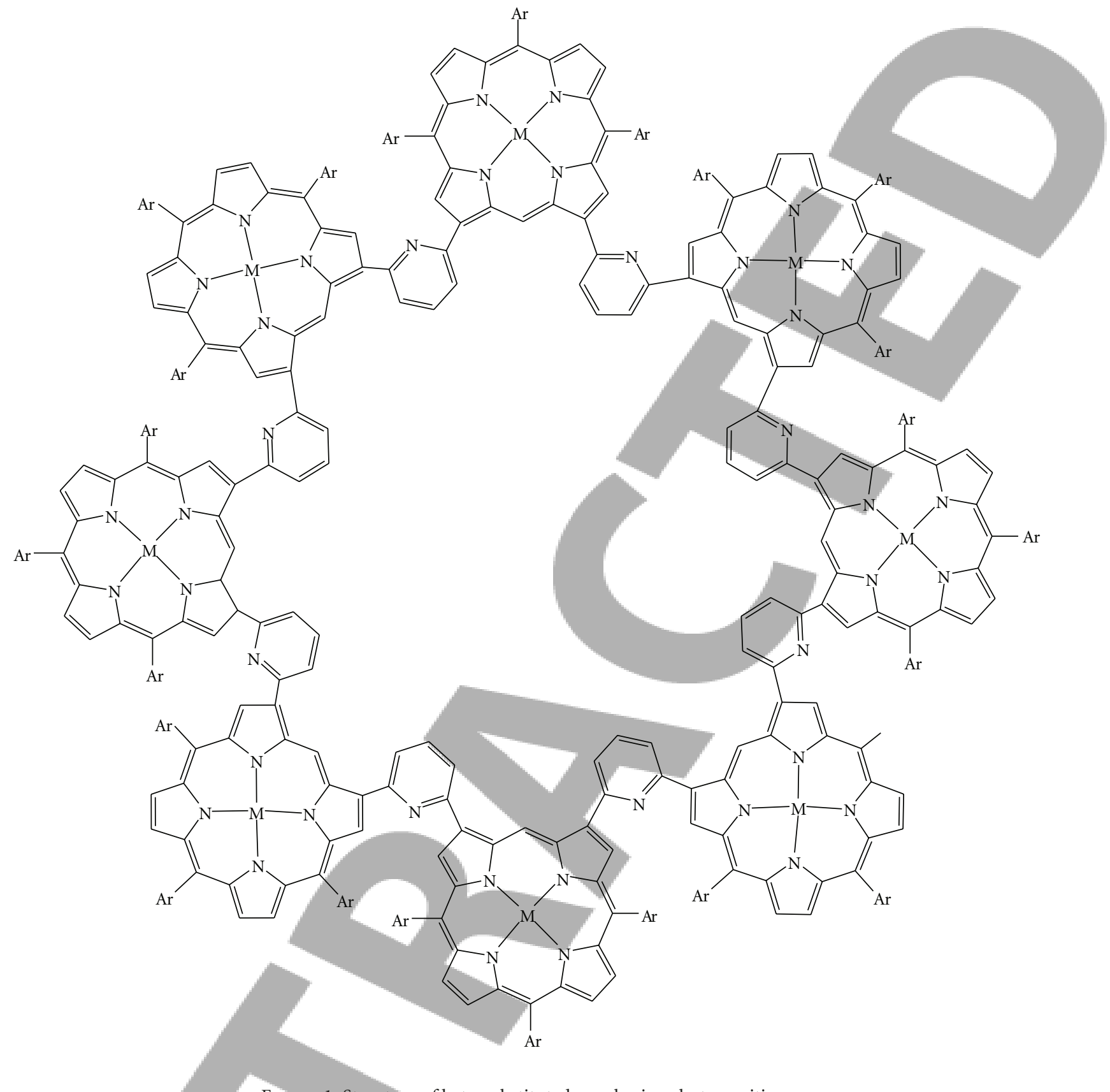

FIGURE 1: Structure of beta-substituted porphyrins photosensitizer.

particles). After getting a viscous paste, it was diluted by slow addition of $2.7 \mathrm{~mL}$ of double distilled water under continuous grinding followed by the addition of $30 \mu \mathrm{L}$ of Triton X-100. The photoanode was fabricated by applying the paste on the conducting surface of FTO electrode using doctor blade technique [24]. The film was kept at $400^{\circ} \mathrm{C}$ in a muffle furnace for $5 \mathrm{~min}$. and the same procedure was repeated three times in order to obtain a thick film $(\sim 10 \mu \mathrm{m})$. The film was dried and sintered at $450^{\circ} \mathrm{C}$ in the muffle furnace for 30 minutes and later allowed to cool to $80^{\circ} \mathrm{C}$. The dye adsorption process was carried out by soaking the hot film $\left(80^{\circ} \mathrm{C}\right)$ in a solution containing $0.5 \mathrm{mM}$ beta substituted porphyrins in ethanol and keeping overnight at ambient temperature. The dye adsorbed electrode was withdrawn from the solution under a stream of $\mathrm{N}_{2}$ gas, and the dye-adsorbed photoanode was immediately wetted with the polymer electrolyte. A platinum counter electrode was prepared on a $2.2 \mathrm{~mm}$ thick FTO conducting glass (Pilkington, TEC7, sheet resistance $\sim 6-8 \Omega / \square$ ) using $7 \mathrm{mM}$ $\mathrm{H}_{2} \mathrm{PtCl}_{6} \cdot 6 \mathrm{H}_{2} \mathrm{O}$ solution in 2-propanol, where $\mathrm{Pt}^{4+}$ ions were reduced thermally at $400^{\circ} \mathrm{C}$. Finally, the platinum-coated counter electrode was placed on the polymer electrolyte 


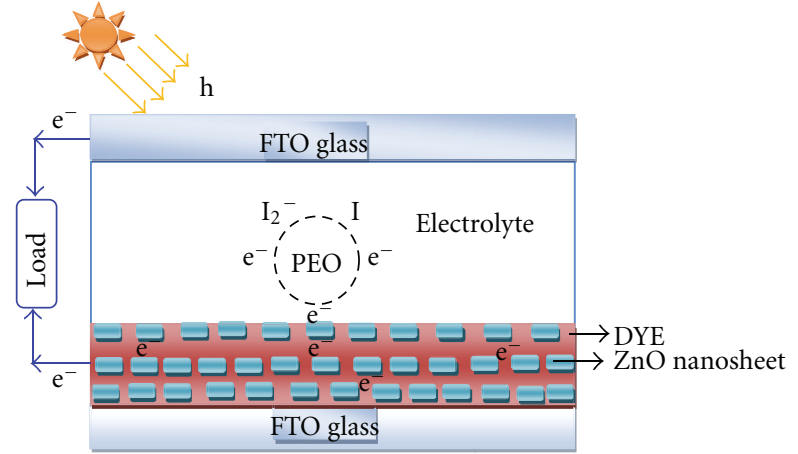

FIGURE 2: Pictorial representation of $\mathrm{ZnO}$ nanosheets photoanode with dye sensitizer.

wetted side of the photoanode to form a sandwiched DSSC. The similar procedure was followed to fabricate DSSC containing photoanode made of $\mathrm{ZnO}$ NPs.

The performance of the DSSCs was evaluated by assessing the photocurrent density-photovoltage $(I-V)$ parameters under simulated solar radiation of $100 \mathrm{~mW} \mathrm{~cm}^{-2}$. The fill factor (FF) and the overall efficiency $(\eta)$ of the DSSCs were calculated by applying the following generalized equations:

$$
\begin{gathered}
\mathrm{FF}=\frac{V_{\mathrm{max}} \cdot I_{\max }}{V_{\mathrm{oc}} \cdot I_{\mathrm{sc}}}, \\
\eta(\%)=\frac{V_{\mathrm{oc}} \cdot I_{\mathrm{sc}} \cdot \mathrm{FF}}{P_{\mathrm{in}}},
\end{gathered}
$$

where $V_{\max }$ and $I_{\max }$ are, respectively, the voltage and current at the maximum power delivering point. Correspondingly, $V_{\mathrm{oc}}$ and $I_{\mathrm{sc}}$ are the open circuit voltage and short circuit current, respectively, delivered by the cell, and $P_{\text {in }}$ is the incident power intensity $\left(100 \mathrm{~mW} \mathrm{~cm}^{-2}\right)$ from solar simulator.

\section{Results and Discussion}

3.1. Spectral Characterizations. The observed UV-Vis absorption spectra of $\mathrm{ZnO}$ NPs and $\mathrm{ZnO}$ NSs are shown in Figure 3. The absorption spectra of $\mathrm{ZnO}$ NSs are similar to $\mathrm{ZnO} N P s$, with maximum absorption at around $358 \mathrm{~nm}$ $(3.46 \mathrm{eV})$ [25]. It is also observable that the intensity of the maximum absorption of the $\mathrm{ZnO}$ nanosheets is less than that of $\mathrm{ZnO}$ nanoparticles. Both $\mathrm{ZnO}$ nanoparticles and $\mathrm{ZnO}$ nanosheets show strong absorbance in the ultraviolet region close to the visible light region of the solar spectrum.

The absorption and transmittance spectrum of the betasubstituted porphyrins dye sensitizer is given in Figure 4. It indicates that the photosensitizer has strong absorbance from 500 to $700 \mathrm{~nm}$ with the maximum absorbance at $635 \mathrm{~nm}$ and more than $60 \%$ of the incident light is being absorbed in the entire wavelength range of $555-670 \mathrm{~nm}$ by $5 \times 10^{-4} \mathrm{M}$ betasubstituted porphyrins. This beta-substituted porphyrin can be used as a photosensitizer in DSSCs. This idea is derived from the broad intense absorption in the visible region of the solar pectrum.

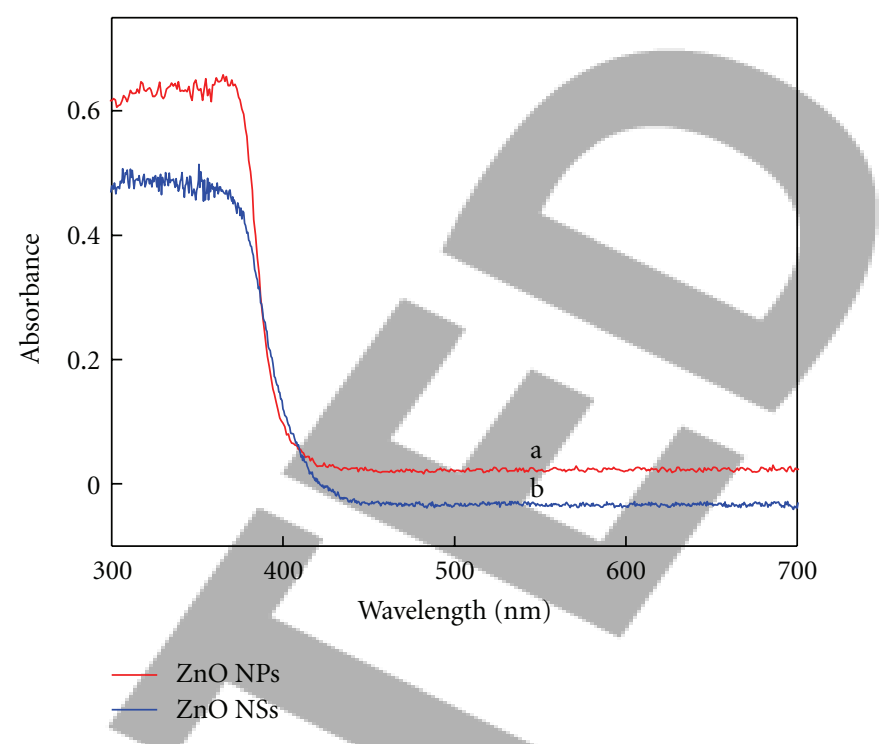

Figure 3: Diffused reflectance spectra of (a) $\mathrm{ZnO}$ NPs and (b) $\mathrm{ZnO}$

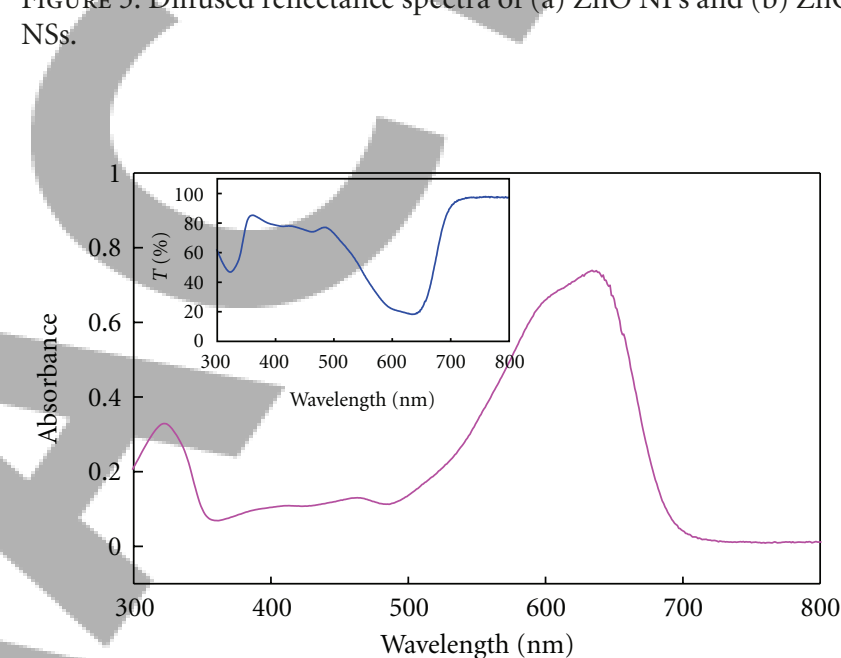

FIgURE 4: Absorption and (inset) transmittance spectra of $0.5 \mathrm{mM}$ beta-substituted porphyrins photosensitizer in DMF.

3.2. Photoluminescence Spectra of $\mathrm{ZnO}$ Nanostructures. Photoluminescence is directly related to electronic structure and transitions. Differences in the electronic behavior between bulk and low-dimensional semiconductors arise due to the difference in the electronic density of states. Photoluminescence spectra and their intensity dependencies can allow one to determine the band gap energy and/or the wavelength of maximum gain, to determine the composition of ternary or quaternary layers, to determine impurity levels and to investigate recombination mechanisms [26]. It is generally known that the room temperature PL spectra for $\mathrm{ZnO}$ usually show three major peaks; a UV peak around $380 \mathrm{~nm}$, a green emission peak around $520 \mathrm{~nm}$, and a red or orange emission around $600 \mathrm{~nm}$. The UV peak is attributed to band-edge emission, while the two broad visible bands are generally attributed to deep-level defects in $\mathrm{ZnO}$ crystal such as vacancies and interstitials of zinc and oxygen [27, 28]. The ZnO NPs and NSs have an intense UV emission peak 
TABLe 1: Photovoltaic parameters of solid-state DSSCs.

\begin{tabular}{lccccccc}
\hline Photoanode & Electrolyte & $J_{\text {sc }}\left(\mathrm{Acm}^{-2}\right)$ & $V_{\mathrm{oc}}(\mathrm{V})$ & $J_{\max }\left(\mathrm{Acm}^{-2}\right)$ & $V_{\max }(\mathrm{V})$ & $\mathrm{FF}$ & $\eta(\%)$ \\
\hline $\mathrm{ZnO} \mathrm{NPs}$ & $\mathrm{I}^{-} / \mathrm{I}_{3}{ }^{-}+\mathrm{PEO}$ & $5.21 \times 10^{-5}$ & 0.32 & $2.80 \times 10^{-5}$ & 0.23 & 0.39 & 0.006 \\
$\mathrm{ZnO} N S s$ & $\mathrm{I}^{-} / \mathrm{I}_{3}{ }^{-}+\mathrm{PEO}$ & $7.66 \times 10^{-5}$ & 0.24 & $3.69 \times 10^{-5}$ & 0.18 & 0.36 & 0.007 \\
$\mathrm{ZnO} \mathrm{NPs}$ & $\mathrm{I}^{-} / \mathrm{I}_{3}{ }^{-}+\mathrm{TiO}_{2} \mathrm{NTs}$ modified PEO & $3.01 \times 10^{-4}$ & 0.38 & $2.82 \times 10^{-4}$ & 0.28 & 0.69 & 0.079 \\
$\mathrm{ZnO} \mathrm{NSs}$ & $\mathrm{I}^{-} / \mathrm{I}_{3}{ }^{-}+\mathrm{TiO}_{2}$ NTs modified PEO & $5.76 \times 10^{-4}$ & 0.37 & $4.27 \times 10^{-4}$ & 0.29 & 0.58 & 0.125 \\
\hline
\end{tabular}

The DSSCs performance was evaluated under $100 \mathrm{~mW} \mathrm{~cm}^{-2}$ of simulated AM1.5 G solar light. $J_{\mathrm{sc}}$ : Short circuit current density; $V_{\mathrm{oc}}$ : Open circuit voltage; $J_{\max }$ : Maximum photocurrent density; $V_{\max }$ : Maximum photovoltage; FF: Fill factor; $\eta$ : Power conversion efficiency; Area of the cell is $1 \mathrm{~cm}^{2}$.

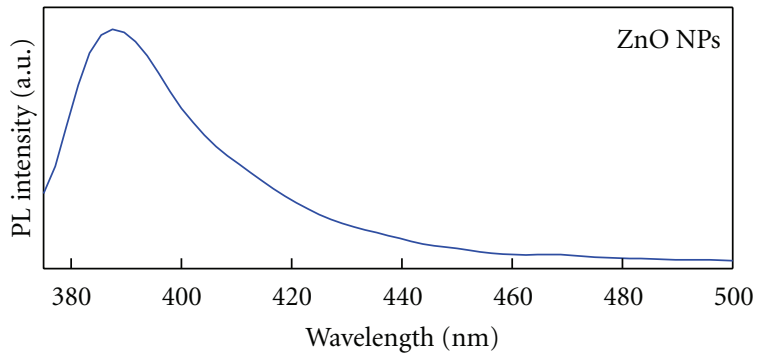

(a)

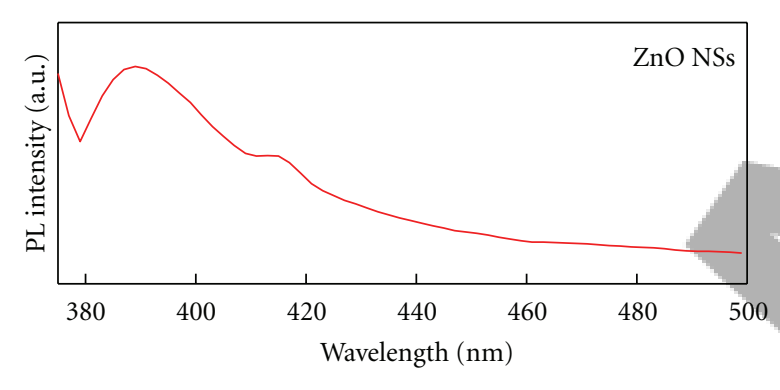

(b)

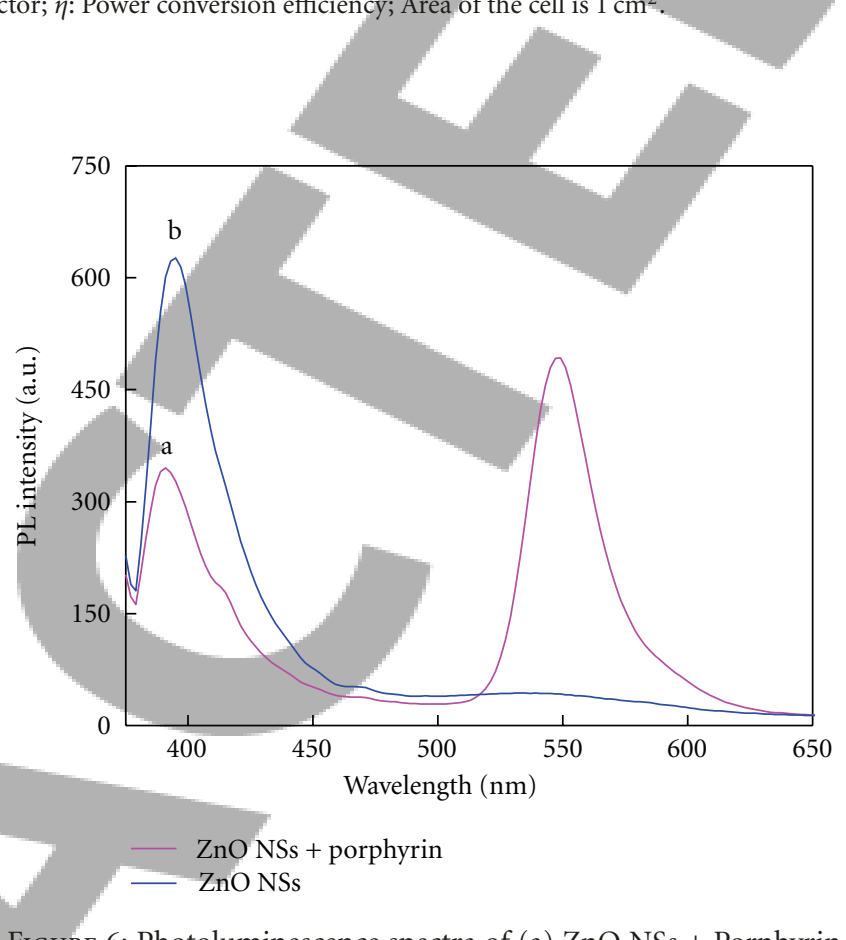

FIGURE 6: Photoluminescence spectra of (a) ZnO NSs + Porphyrin sensitizer and (b) ZnO NSs in DMF.
FIgURE 5: Photoluminescence spectra of (a) ZnO NPs and (b) ZnO NSs in DMF.

and a weak broad visible emission (Figures 5(a) and 5(b)). In Figure 5(b) an intense peak at $390 \mathrm{~nm}$ for $\mathrm{ZnO}$ NSs in DMF is noticed which may be due to the presence of large amount of oxygen vacancies created during the synthesis in the atmosphere of deficient oxygen.

The PL spectra of pure ZnO NSs with substituted porphyrins dye and $\mathrm{ZnO}$ NS are given in Figures 6(a) and 6(b). We notice that the UV emission peak at $3.25 \mathrm{eV}(380 \mathrm{~nm})$ is present both in $\mathrm{ZnO}$ NSs and dye-incorporated sample; the intensity of the UV emission peak is less intense. The dyeincorporated sample shows that an intense defect-related emission peak at $2.48 \mathrm{eV}(500 \mathrm{~nm})$ indicates that there is a great fraction of oxygen vacancies. A higher surface area to volume ratio for thinner nanosheets will favor a higher level of surface and subsurface oxygen vacancy [29]. The sharp and intense UV emission, the weak emission related to ionized oxygen vacancies, and the absence of the well-known stronger and broader emission in the yellow band illustrates the good crystallization quality and high stoichiometric nature of the obtained products [30].
3.3. X-Ray Diffraction Analysis. All the diffraction peaks observed in the XRD patterns of the $\mathrm{ZnO}$ NPs and $\mathrm{ZnO}$ NSs (Figures $7(\mathrm{a})$ and $7(\mathrm{~b})$ ) can be indexed to those of wurtzite- (hexagonal-) structured $\mathrm{ZnO}$ (space group P63mc) with cell parameters $a=3.249 \AA$ and $c=5.206 \AA$, which is in good agreement with the data obtained from JCPD file no. 79-0206 from the orientation attachment theory proposed by Penn and Banfield [31, 32] and $\mathrm{Xu}$ et al. [33]. No characteristic peaks of other impurities are detected in the pattern, suggesting that single-phase $\mathrm{ZnO}$ only formed in this method. In general, $\mathrm{ZnO}$ exhibits (002)-preferred orientation (facets) with the $c$-axis perpendicular to the substrate due to the lower surface free energy for the (002) plane consequently, (002)-oriented $\mathrm{ZnO}$ films have been widely studied [34]. Recently, many theoretical and experimental studies concerning other crystalline planes such as (110)- and (100)-faceted $\mathrm{ZnO}$ films have also been carried out by many researchers. It is found that different crystalline orientations possess different electronic [35], optical [36], and acoustic $[37,38]$ properties. The XRD patterns well agree with those reported in the literature $[39,40]$. The intensity of the (101) planes is observed to be much stronger than (002) and (100) plane in the ZnO NSs. The intensity of the XRD pattern of 


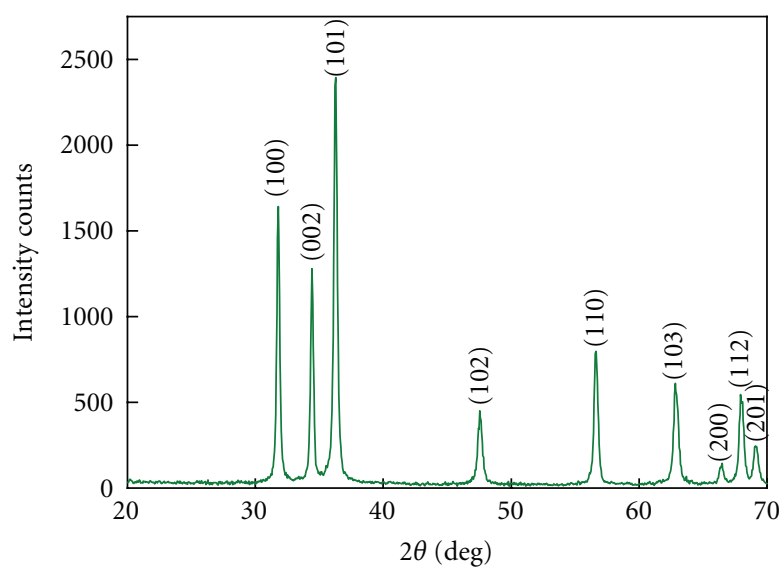

(a)

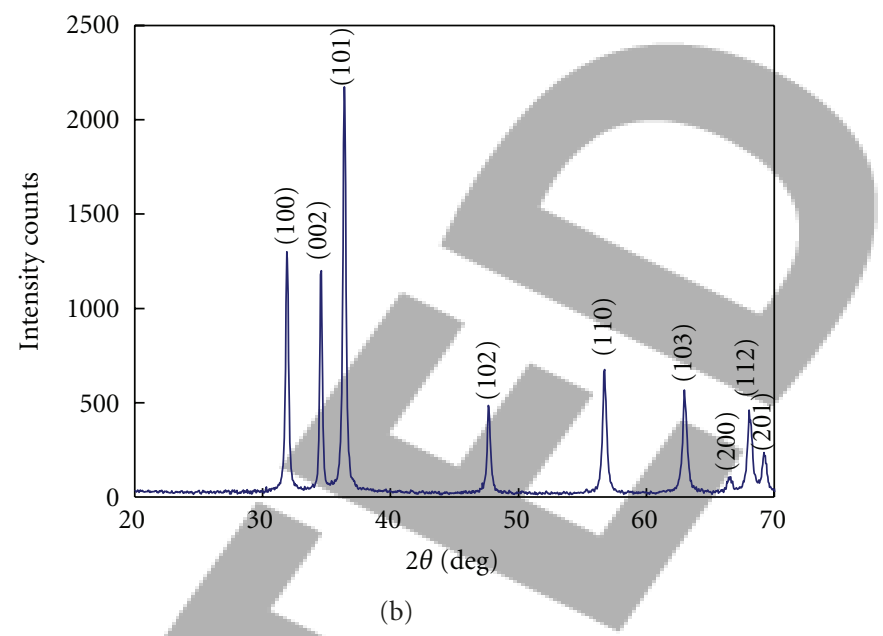

FIGURE 7: X-ray diffraction patterns of (a) ZnO NPs and (b) ZnO NSs.
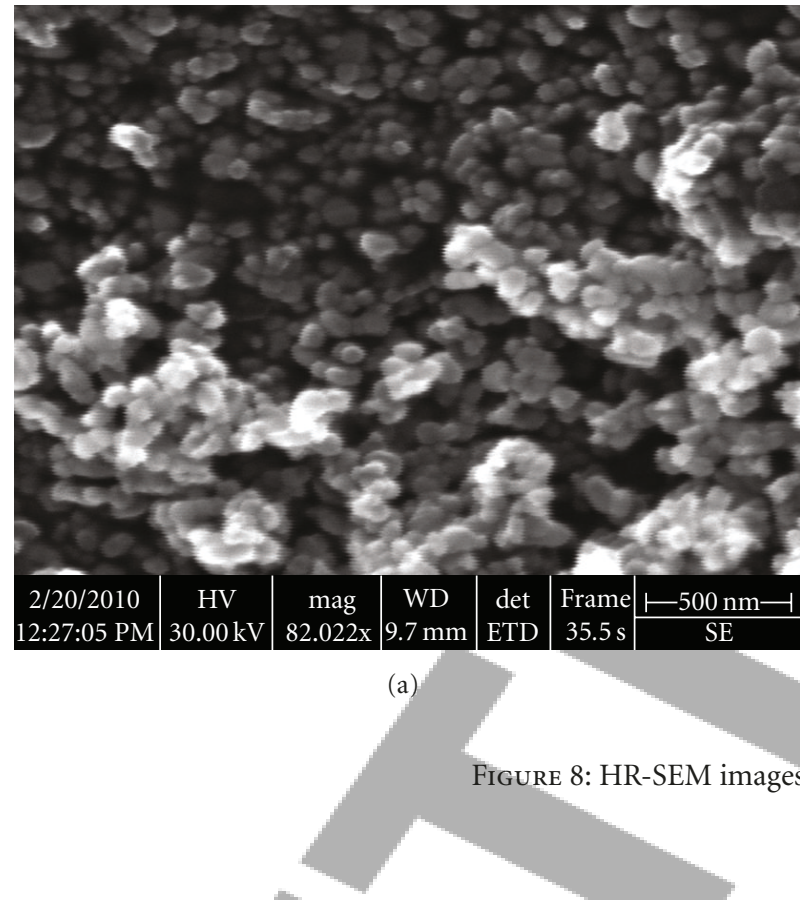

$\mathrm{ZnO}$ NSs is slightly lower than that of $\mathrm{ZnO}$ NPs. But it is noticed that the intensity of (002) is almost equal to that of (100) peak.

3.4. SEM Analysis of ZnO Nanostructures. The HR-SEM images of $\mathrm{ZnO} \mathrm{NPs}$ and $\mathrm{ZnO}$ NSs are shown in Figures 8 (a) and $8(\mathrm{~b})$, respectively. The $\mathrm{ZnO}$ NPs are spherical in shape with size range varying between 20 and $25 \mathrm{~nm}$. The close assimilation of the ZnO NSs in Figure 8(b) displays the detailed morphologies of the hexagonal plates, where two adjacent contacting surfaces are rather smooth and some of them have intersecting growth. The ZnO NSs are all uniform in size with well-defined shape, whose thicknesses are in between 50 and $150 \mathrm{~nm}$. They have high-density uniform coverage all over the sample surface area as observed by the HR-SEM images.

3.5. Photovoltaic Performance of DSSCs. The photovoltaic performances of solid-state DSSCs consisting of photoanodes with $\mathrm{ZnO}$ nanostructures of different morphology were investigated in an irradiation of $100 \mathrm{~mW} \mathrm{~cm}^{-2}$ (Simulated by AM1.5G filter). The $I-V$ characteristics of the $\mathrm{ZnO}$ nanoparticles and $\mathrm{ZnO}$ nanosheets based solid-state DSSCs in combination with bare PEO and $\mathrm{TiO}_{2}$ NTs modified PEO polymer electrolytes are shown in Figure 9 and their photovoltaic parameters are given in Table 1. The photopotentials of DSSC ZnO NSs are slightly less than those of 


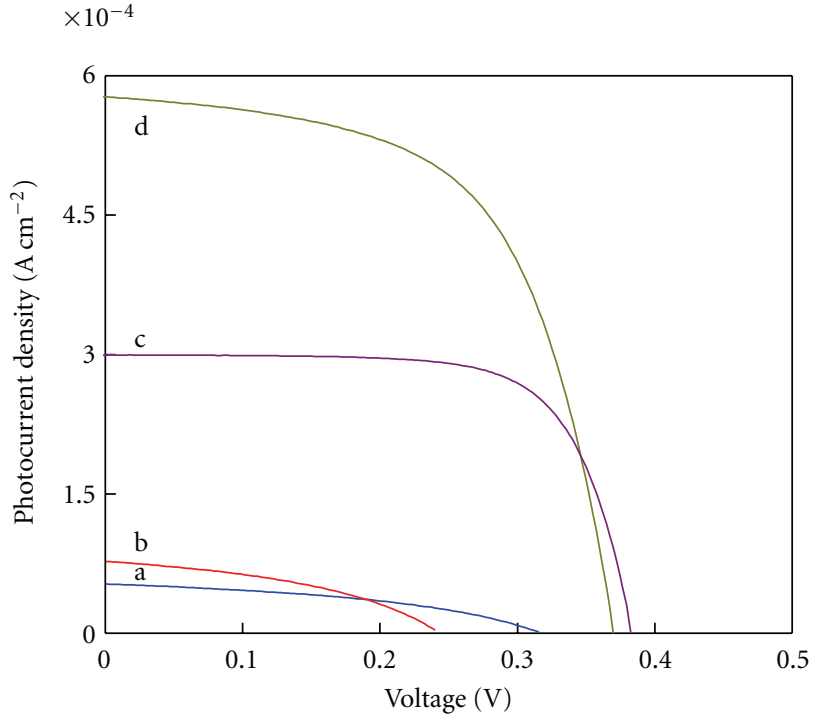

FIGURE 9: $I-V$ profile of DSSCs consisting of (a) ZnO NPs photoanode + PEO electrolyte, (b) ZnO NSs photoanode + PEO electrolyte, (c) $\mathrm{ZnO}$ NPs photoanode $+\mathrm{TiO}_{2} \mathrm{NTs}$ modified PEO electrolyte, and (d) $\mathrm{ZnO}$ NSs photoanode $+\mathrm{TiO}_{2}$ NTs modified PEO electrolyte.

$\mathrm{ZnO}$ NPs, and the photocurrents of the DSSC ZnO NSs are also remarkably less than those of $\mathrm{ZnO}$ NPs. Higher photocurrent with $\mathrm{ZnO}$ NSs photoanode suggests that NSs have better contact with the electrolyte, which give easy transfer of electrons between the electrodes. Significantly, higher photocurrents observed in $\mathrm{TiO}_{2} \mathrm{NT}$ s modified PEO electrolyte based DSSCs could be attributed to higher electrical conductivity of the electrolyte.

From Table 1, it can be inferred that all photovoltaic parameters of solid-state DSSCs based on $\mathrm{TiO}_{2}$ NTs modified PEO electrolyte are higher than those of cells based on unmodified PEO electrolyte. There is almost 2-fold increment in the fill factor of the $\mathrm{TiO}_{2}$ NTs modified PEO based DSSCs compared to that of the unmodified one for both ZNO NPs and ZnO NS. The increase in the fill factor could be due to the reduction in the crystallinity of the electrolyte thereby increasing the ionic conductivity of the PEO polymer electrolyte, which is attributed to the presence of $\mathrm{TiO}_{2} \mathrm{NTs}$ [23], subsequently leading to the increase in photovoltaic performance of the DSSCs. From Table 1, it can also be inferred that the short circuit photocurrent density $\left(J_{\mathrm{sc}}\right)$ and the open circuit voltage $\left(V_{\mathrm{oc}}\right)$ of $\mathrm{ZnO}$ NPs based DSSCs with $\mathrm{TiO}_{2}$ NTs modified PEO electrolyte are $3.01 \times 10^{-4} \mathrm{~A} \mathrm{~cm}^{-2}$ and $0.38 \mathrm{~V}$, respectively, while those of $\mathrm{ZnO}$ NS based DSSCs with TNT modified PEO electrolyte are $5.76 \times 10^{-4} \mathrm{~A} \mathrm{~cm}^{-2}$ and $0.37 \mathrm{~V}$, respectively. The ZnO NS based DSSCs exhibits higher efficiency $(\eta)$ of $0.125 \%$ when compared to that of $\mathrm{ZnO}$ NPs based DSSCs $(0.079 \%)$ in the presence of $\mathrm{TiO}_{2}$ NTs modified solid-state polymer electrolyte. This result clearly indicates an effective increase in the conversion efficiency of the cell by tuning the morphology of the $\mathrm{ZnO}$ nanostructures. The increase in the efficiency is attributed to the fast electron diffusion within the nanosheets, which

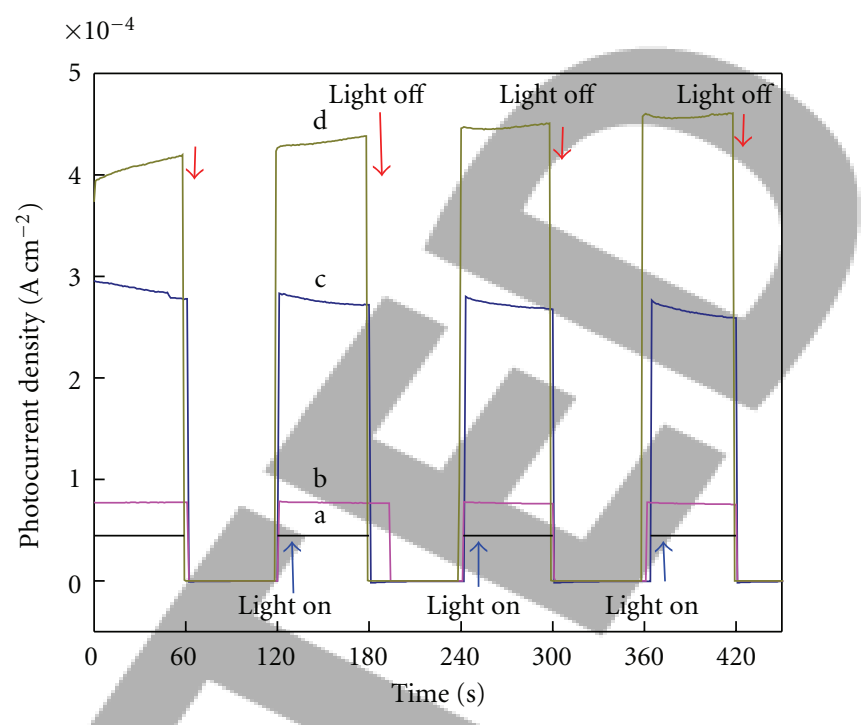

Figure 10: Photocurrent-time ( $I-T)$ profile of solid-state DSSCs having (a, c) ZnO NPs and (b, d) ZnO NS photoanodes with PEO $(\mathrm{a}, \mathrm{b})$ and $\mathrm{TiO}_{2}$ NTs modified PEO (c, d) electrolytes.

is expected to enhance the $J_{\text {sc }}[19,33,41,42]$. The efficiency of the $\mathrm{ZnO}$ NS based solid-state DSSC is low when compared with conventional ZnO NS based DSSCs [43]. This is mainly due to the nature of photosensitizer used and heterogeneous electrolyte employed in the present investigation.

The stability and reproducibility of photocurrent generation concerned with $\mathrm{ZnO} \mathrm{NPs}$ and $\mathrm{ZnO} \mathrm{NS}$ based DSSCs were studied through chronoamperometry and the results are shown in Figure 10. The photocurrent-time $(I-T)$ profiles differ between them in agreement with their $I-V$ characteristics. Variations in the solar energy to electrical energy conversion efficiencies found between them can be attributed to the differences in the morphology and conductivity of polymer electrolytes. The $\mathrm{ZnO}$ NS electrode exhibits 1.6-fold higher steady-state photocurrent than that of the $\mathrm{ZnO}$ NPs electrode. It implies that the nanosheets based photoanode has the capability transfering more photocurrent than the nanoparticles based one. As far as the electrolyte is concerned, $\mathrm{TiO}_{2}$ NTs modified PEO electrolyte based DSSCs exhibit 4-fold increment in the photocurrent generation when compared to that of unmodified PEO electrolyte based DSSC. This is attributed to the incorporation of $\mathrm{TiO}_{2} \mathrm{NTs}$ in PEO, which facilitate charge transfer. In the $\mathrm{ZnO}$ NPs electrode based DSSCs, as soon as the light is turned on, the photocurrent rises quickly to a maximum value. When the light is turned off, sudden fall in photocurrent appears before equilibrium is reached in the dark. It is because the photogenerated electrons are trapped under illumination, recombining with holes, and detrapped in the dark.

\section{Summary}

$\mathrm{TiO}_{2}$ NTs modified PEO electrolyte based solid-state DSSCs were fabricated using $\mathrm{ZnO}$ NPs and $\mathrm{ZnO}$ NSs photoanode in the presence of beta-substituted porphyrins sensitizer 
and their photovoltaic performance was evaluated under AM1.5G simulated solar irradiation. The efficiency of the $\mathrm{ZnO}$ NSs based DSSCs was better than that of the ZnO NPs based one. This is due to the rapid diffusion of electrons within the nanosheets. Incorporation of the $\mathrm{TiO}_{2} \mathrm{NT}$ fillers in PEO electrolyte further enhanced the performance of the DSSCs, which is due to the increase in conductivity and reduction in crystallinity of the PEO electrolyte. In the present study, the efficiency of the ZnO NSs based solidstate DSSCs with beta-substituted porphyrins sensitizer is lower than that of $\mathrm{ZnO}$ NSs based DSSCs employing liquid electrolyte. By employing an efficient dye sensitizer, the performance of the solid-state DSSCs can match with the DSSCs having liquid electrolytes.

\section{Acknowledgment}

The author wish to thank the Saveetha School of Engineering, Saveetha University, Chennai for supporting this work financially.

\section{References}

[1] B. O’Regan and M. Grätzel, "A low-cost, high-efficiency solar cell based on dye-sensitized colloidal $\mathrm{TiO}_{2}$ films," Nature, vol. 353, no. 6346, pp. 737-740, 1991.

[2] A. Hagfeldt and M. Grätzel, "Molecular photovoltaics," Accounts of Chemical Research, vol. 33, no. 5, pp. 269-277, 2000.

[3] M. Grätzel, "Photoelectrochemical cells," Nature, vol. 414, no. 6861, pp. 338-344, 2001.

[4] L. Huang, S. Wright, S. Yang, D. Shen, B. Gu, and Y. Du, " $Z$ nO well-faceted fibers with periodic junctions," Journal of Physical Chemistry B, vol. 108, no. 52, pp. 19901-19903, 2004.

[5] T. Sagawa, S. Yoshikawa, and H. Imahori, "One-dimensional nanostructured semiconducting materials for organic photovoltaics," Journal of Physical Chemistry Letters, vol. 1, no. 7, pp. 1020-1025, 2010.

[6] K. Keis, L. Vayssieres, H. Rensmo, S. E. Lindquist, and A. Hagfeldt, "Photoelectrochemical properties of nano- to microstructured $\mathrm{ZnO}$ electrodes," Journal of the Electrochemical Society, vol. 148, no. 2, pp. A149-A155, 2001.

[7] R. Katoh, A. Furube, T. Yoshihara et al., "Efficiencies of electron injection from excited $\mathrm{N} 3$ dye into nanocrystalline semiconductor $\left(\mathrm{ZrO}_{2}, \mathrm{TiO}_{2}, \mathrm{ZnO}, \mathrm{Nb}_{2} \mathrm{O}_{5}, \mathrm{SnO}_{2}, \mathrm{In}_{2} \mathrm{O}_{3}\right)$ films," Journal of Physical Chemistry B, vol. 108, no. 15, pp. 4818-4822, 2004.

[8] H. Horiuchi, R. Katoh, K. Hara et al., "Electron injection efficiency from excited $\mathrm{N} 3$ into nanocrystalline $\mathrm{ZnO}$ films: effect of $\left(\mathrm{N} 3-\mathrm{Zn}^{2+}\right)$ aggregate formation," Journal of Physical Chemistry B, vol. 107, no. 11, pp. 2570-2574, 2003.

[9] P. Y. Wu, J. Pike, F. Zhang, and S. W. Chan, "Low-temperature synthesis of zinc oxide nanoparticles," International Journal of Applied Ceramic Technology, vol. 3, no. 4, pp. 272-278, 2006.

[10] Q. Zhang, C. S. Dandeneau, X. Zhou, and C. Cao, "ZnO nanostructures for dye-sensitized solar cells," Advanced Materials, vol. 21, no. 41, pp. 4087-4108, 2009.

[11] Z. Zhang, M. Lu, H. Xu, and W. S. Chin, "Shape-controlled synthesis of zinc oxide: a simple method for the preparation of metal oxide nanocrystals in non-aqueous medium," Chemistry: A European Journal, vol. 13, no. 2, pp. 632-638, 2007.
[12] L. E. Greene, B. D. Yuhas, M. Law, D. Zitoun, and P. Yang, "Solution-grown zinc oxide nanowires," Inorganic Chemistry, vol. 45, no. 19, pp. 7535-7543, 2006.

[13] B. Pradhan, S. K. Batabyal, and A. J. Pal, "Vertically aligned $\mathrm{ZnO}$ nanowire arrays in Rose Bengal-based dye-sensitized solar cells," Solar Energy Materials and Solar Cells, vol. 91, no. 9, pp. 769-773, 2007.

[14] A. J. Cheng, Y. Tzeng, Y. Zhou et al., "Thermal chemical vapor deposition growth of zinc oxide nanostructures for dyesensitized solar cell fabrication," Applied Physics Letters, vol. 92, no. 9, Article ID 092113, 2008.

[15] T. Sasaki, Y. Ebina, Y. Kitami, M. Watanabe, and T. Oikawa, "Two-dimensional diffraction of molecular nanosheet crystallites of titanium oxide," Journal of Physical Chemistry B, vol. 105, no. 26, pp. 6116-6121, 2001.

[16] T. Sasaki and M. Watanabe, "Semiconductor nanosheet crystallites of quasi- $\mathrm{TiO}_{2}$ and their optical properties," Journal of Physical Chemistry B, vol. 101, no. 49, pp. 10159-10161, 1997.

[17] J. Q. Hu, Y. Bando, J. H. Zhan, Y. B. Li, and T. Sekiguchi, "Two-dimensional micrometer-sized single-crystalline $\mathrm{ZnO}$ thin nanosheets," Applied Physics Letters, vol. 83, no. 21, pp. 4414-4416, 2003.

[18] E. Hosono, S. Fujihara, I. Honma, and H. Zhou, "The fabrication of an upright-standing zinc oxide nanosheet for use in dye-sensitized solar cells," Advanced Materials, vol. 17, no. 17, pp. 2091-2094, 2005.

[19] A. F. Nogueira, J. R. Durrant, and M. A. De Paoli, "Dyesensitized nanocrystalline solar cells employing a polymer electrolyte," Advanced Materials, vol. 13, no. 11, pp. 826-830, 2001.

[20] U. Bach, D. Lupo, P. Comte et al., "Solid-state dye-sensitized mesoporous $\mathrm{TiO}_{2}$ solar cells with high photon-to-electron conversion efficiencies," Nature, vol. 395 , no. 6702, pp. 583$585,1998$.

[21] J. Zhang, H. Liu, Z. Wang, N. Ming, Z. Li, and A. S. Biris, "Polyvinylpyrrolidone-directed crystallization of $\mathrm{ZnO}$ with tunable morphology and bandgap," Advanced Functional Materials, vol. 17, no. 18, pp. 3897-3905, 2007.

[22] Y. Lan, X. Gao, H. Zhu et al., "Titanate nanotubes and nanorods prepared from rutile powder," Advanced Functional Materials, vol. 15, no. 8, pp. 1310-1318, 2005.

[23] T. Stergiopoulos, I. M. Arabatzis, G. Katsaros, and P. Falaras, "Binary polyethylene oxide/titania solid-state redox electrolyte for highly efficient nanocrystalline $\mathrm{TiO}_{2}$ photoelectrochemical cells," Nano Letters, vol. 2, no. 11, pp. 1259-1261, 2002.

[24] M. K. Nazeeruddin, A. Kay, I. Rodicio et al., "Conversion of light to electricity by cis- $\mathrm{X}_{2}$ bis $\left(2,2^{\prime}\right.$-bipyridyl- $4,4^{\prime}$ dicarboxylate)ruthenium(II) charge-transfer sensitizers ( $\mathrm{X}=$ $\mathrm{Cl}^{-}, \mathrm{Br}^{-}, \mathrm{I}^{-}, \mathrm{CN}^{-}$, and $\mathrm{SCN}$ ) on nanocrystalline $\mathrm{TiO}_{2}$ electrodes," Journal of the American Chemical Society, vol. 115, no. 14, pp. 6382-6390, 1993.

[25] Z. H. Liang, Y. J. Zhu, G. F. Cheng, and Y. H. Huang, "Synthesis of $\mathrm{ZnO}$ nanosheets by room-temperature decomposition of a layered precursor synthesized by microwave heating," Journal of Materials Science, vol. 42, no. 2, pp. 477-482, 2007.

[26] X. T. Zhang, Y. C. Liu, J. Y. Zhang et al., "Structure and photoluminescence of Mn-passivated nanocrystalline $\mathrm{ZnO}$ thin films," Journal of Crystal Growth, vol. 254, no. 1-2, pp. 80-85, 2003.

[27] V. A. L. Roy, A. B. Djurišić, H. Liu et al., "Magnetic properties of Mn doped $\mathrm{ZnO}$ tetrapod structures," Applied Physics Letters, vol. 84, no. 5, pp. 756-758, 2004. 
[28] C. Ronning, P. X. Gao, Y. Ding, Z. L. Wang, and D. Schwen, "Manganese-doped $\mathrm{ZnO}$ nanobelts for spintronics," Applied Physics Letters, vol. 84, no. 5, pp. 783-785, 2004.

[29] P. Yang, H. Yan, S. Mao et al., "Controlled growth of $\mathrm{ZnO}$ nanowires and their optical properties," Advanced Functional Materials, vol. 12, no. 5, pp. 323-331, 2002.

[30] X. Gao, X. Li, and W. Yu, "Flowerlike $\mathrm{ZnO}$ nanostructures via hexamethylenetetramine-assisted thermolysis of zincethylenediamine complex," Journal of Physical Chemistry B, vol. 109, no. 3, pp. 1155-1161, 2005.

[31] J. F. Banfield, S. A. Welch, H. Zhang, T. T. Ebert, and R. L. Penn, "Aggregation-based crystal growth and microstructure development in natural iron oxyhydroxide biomineralization products," Science, vol. 289, no. 5480, pp. 751-754, 2000.

[32] R. L. Penn and J. F. Banfield, "Imperfect oriented attachment: dislocation generation in defect-free nanocrystals," Science, vol. 281, no. 5379, pp. 969-971, 1998.

[33] F. Xu, M. Dai, Y. Lu, and L. Sun, "Hierarchical ZnO nanowirenanosheet architectures for high power conversion efficiency in dye-sensitized solar cells," Journal of Physical Chemistry C, vol. 114, no. 6, pp. 2776-2782, 2010.

[34] J. I. Hong, J. Bae, Z. L. Wang, and R. L. Snyder, "Roomtemperature, texture-controlled growth of $\mathrm{ZnO}$ thin films and their application for growing aligned $\mathrm{ZnO}$ nanowire arrays," Nanotechnology, vol. 20, no. 8, Article ID 085609, 2009.

[35] D. H. Cho, J. H. Kim, B. M. Moon, Y. D. Jo, and S. M. Koo, "Control of a- and c-plane preferential orientations of $\mathrm{ZnO}$ thin films," Applied Surface Science, vol. 255, no. 6, pp. 34803484, 2009.

[36] M. Wang and L. Zhang, "The influence of orientation on the photoluminescence behavior of $\mathrm{ZnO}$ thin films obtained by chemical solution deposition," Materials Letters, vol. 63, no. 2, pp. 301-303, 2009.

[37] M. S. Lee, S. Wu, Z. X. Lin, and R. Ro, "Bulk acoustic wave analysis of crystalline-plane-oriented aluminum nitride films," Japanese Journal of Applied Physics, vol. 46, no. 10A, pp. 67196726, 2007.

[38] X. Ju, W. Feng, K. Varutt, T. Hori, A. Fujii, and M. Ozaki, "Fabrication of oriented $\mathrm{ZnO}$ nanopillar self-assemblies and their application for photovoltaic devices," Nanotechnology, vol. 19, no. 43, Article ID 435706, 2008.

[39] N. Wang, L. Jiang, H. Peng, and G. Li, "Synthesis of $\mathrm{ZnO}$ nanostructures composed of nanosheets with controllable morphologies," Crystal Research and Technology, vol. 44, no. 3, pp. 341-345, 2009.

[40] B. Cao, W. Cai, Y. Li, F. Sun, and L. Zhang, "Ultravioletlight-emitting $\mathrm{ZnO}$ nanosheets prepared by a chemical bath deposition method," Nanotechnology, vol. 16, no. 9, pp. 17341738, 2005.

[41] M. S. Akhtar, M. A. Khan, M. S. Jeon, and O. B. Yang, "Controlled synthesis of various $\mathrm{ZnO}$ nanostructured materials by capping agents-assisted hydrothermal method for dyesensitized solar cells," Electrochimica Acta, vol. 53, no. 27, pp. 7869-7874, 2008.

[42] X. Wang, Z. Tian, T. Yu et al., "Effective electron collection in highly (110)-oriented $\mathrm{ZnO}$ porous nanosheet framework photoanode," Nanotechnology, vol. 21, no. 6, Article ID 065703, 2010.

[43] S. M. Ahmed, J. Leduc, and S. F. Haller, "Photoelectrochemical and impedance characteristics of specular hematite. 1. Photoelectrochemical, parallel conductance, and trap rate studies," Journal of Physical Chemistry, vol. 92, no. 23, pp. 6655-6660, 1988.

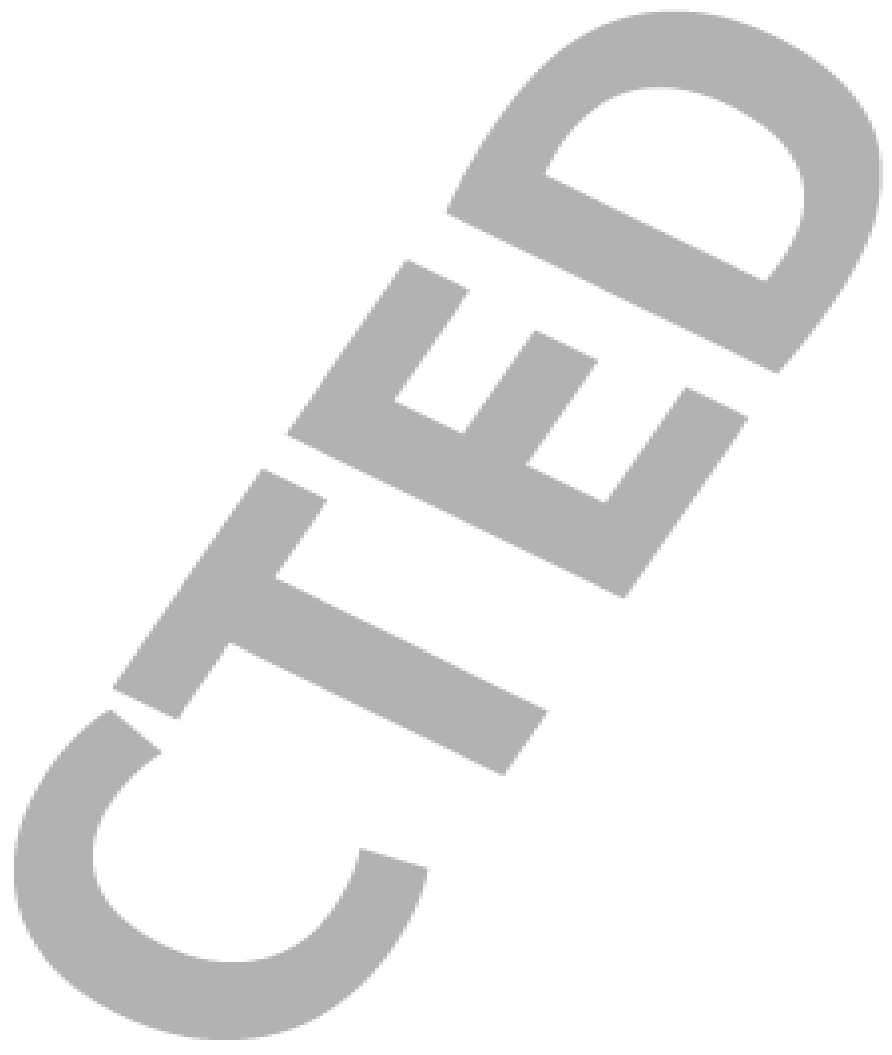

